\title{
Le dialecte natal: analyse de l'opinion des intellectuels et des villageois de Lituanie
}

\author{
Genovaité KaČiušKienè \\ Université de Šiauliai, Faculté des sciences humaines, \\ P. Višinskio 38,LT-76352 Šiauliai, geno@splius.lt
}

\begin{abstract}
Članek temelji na izsledkih raziskave andragoške fakultete za humanistične študije šiauliajške univerze v Litvi (Faculty of Humanities of the University of Adult Education of Šiauliai), katere namen je bil ugotoviti: (1) kako mestno okolje in družba vplivata na pojmovanje narečja in njegovo rabo, (2) koliko šiauliajških intelektualcev srednjih let, ki so se pred nekaj leti izselili iz rojstne regije, še zmeraj govori v narečju ali celo v knjižni litovščini in (3) kakšen je njihov odnos do različnih narečij.
\end{abstract}

In the article, based on a research questionnaire conducted in the Faculty of Humanities of the University of Adult Education of Šauliai, we attempt to ascertain, 1) how the city's environment and social dependence influence the conception of dialect and its usage, 2) how many intellectuals of Šiauliai of a mature age, who moved from their native region several years ago, still speak dialect or even standard Lithuanian and 3) what their attitude is toward different dialects.

Ključne besede: litovščina, narečje, identiteta, raziskovalna vprašalnica, sociolingvistična analiza

Key words: Lithuanian, dialect, identity, research questionnaire, sociolinguistic analysis

\section{Introduction}

Le lituanien (avec le letton) est l'une des deux seules langues, qui subsiste de la famille balte du groupe des langues indo-européennes. ${ }^{1}$

${ }^{1}$ L'écriture latine a été adoptée au XVIème siècle et l'alphabet contient 32 lettres. Res-
semblances avec d'autres langues: verbes perfectifs et imperfectifs comme dans les 
Le lituanien comporte deux grands groupes dialectaux : celui de l'ouest, la Basse-Lituanie ou Samogites (Žemaitija), et celui de l'est, la Haute-Lituanie (Aukštaitija), qui a donné naissance à la langue littéraire moderne. Les différences entre ces deux groupes de dialectes sont importantes, la solution est donc d'utiliser la langue littéraire pour être bien compris (V. Ambrazas 1997: 5).

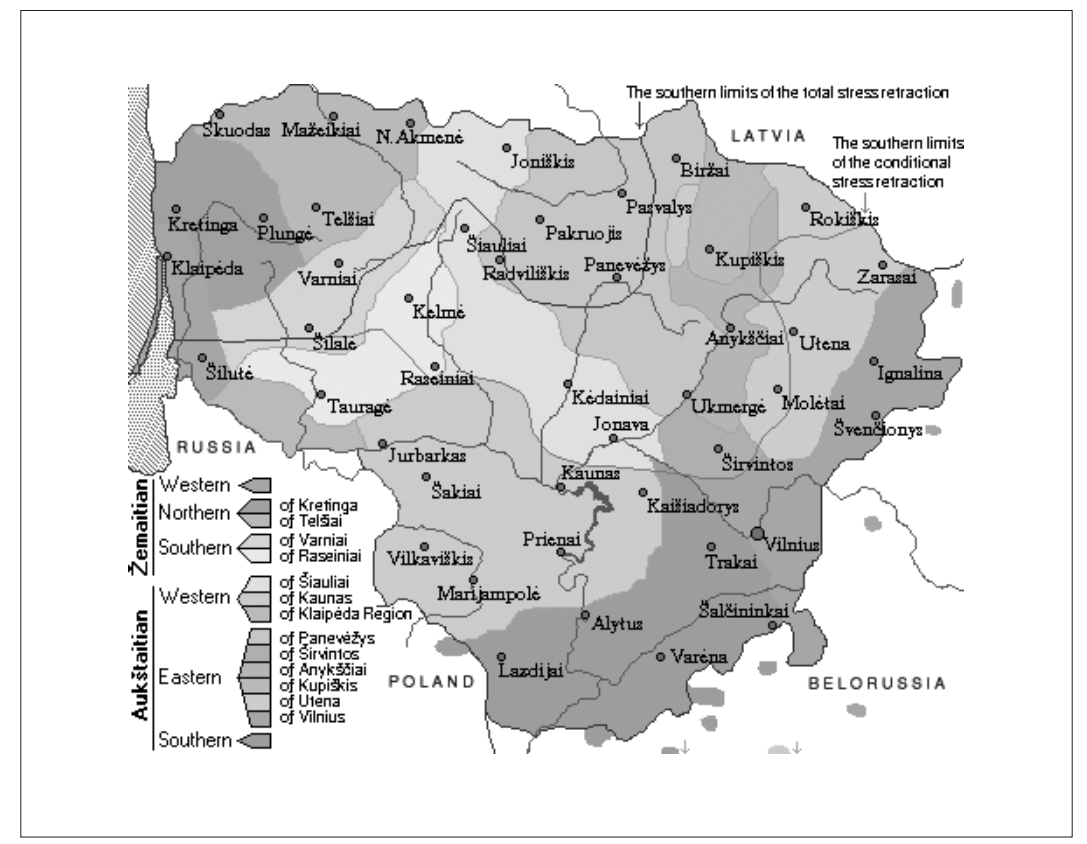

Carte 1. Les dialectes lituaniens. ${ }^{2}$ Préparée par l'Institut de la langue lituanienne (www.lrytas.lt/str_foto_galerija.asp?id=24045).

Il y a deux objectifs de cet article : 1) analyser quelle influence une ville et l'éducation exercent sur le dialecte et son emploi, 2) comment des intellectuels non linguistes considèrent les dialectes du lituanien et ses particularités.

langues slaves ou le grec; absence d'articles définis et indéfinis comme en russe ou en latin par exemple; double déclinaison des adjectifs (définis et indéfinis) comme en islandais, russe, etc. nombreux mots indo-européens ressemblant au vocabulaire slave, latin, germanique, grec; présence d'un datif absolu pour le sujet dans les phrases participiales rappelant l'ablativus absolutus en latin; système de préverbes très complexe comme dans les langues slaves ou germaniques, etc (P.U. Dini 2000: 128-179).

${ }^{2}$ La ligne N. Akmenè, Šiauliai, Raseiniai, Tauragè sépare la Basse-Lituanie de la HauteLituanie (R. Bacevičiūtè 2004: 29). 


\section{Methodologie de l'expérience}

Au cours de l'analyse on a présenté un questionnaire anonyme aux auditeurs de l'Université de Troisième Âge de Šiauliai, ${ }^{3}$ originaires de différentes localités dialectales de la Lituanie, mais habitant déjà depuis quelques dizaines d'années une ville de taille moyenne.

Pour cette raison on a proposé 10 questions à répondre:

Est-ce que vous parlez votre dialecte natal?

Qui est ce qui vous a appris à parler le dialecte?

Pourquoi est-ce que vous parlez (ne parlez pas) le dialecte?

Est-ce que vous trouvez votre dialecte natal beau (pas beau)? Pourquoi?

Est-ce que vous aimez (n'aimez pas) parler le dialecte?

Pourquoi est-ce que vous aimez (n'aimez pas) parler le dialecte?

D'après vous, quand convient-il de parler le dialecte.

D'après vous, quand ne convient-il pas de parler le dialecte?

Quand est-ce que vous parlez le dialecte?

Vos enfants (si vous en avez) parlent-ils votre dialecte?

220 personnes interrogées ont rempli les questionnaires, parmi eux il y avait 120 Hauts-Lituaniens et 100 Bas-Lituaniens.

\section{Traitement des résultats}

Toutes les réponses reçues peuvent être classées en 4 groupes selon: 1) la situation linguistique dans la ville de Šiauliai en Lituanie, 2) la motivation de parler le dialecte, 3) la fonction esthétique du dialecte et 4) les localités d'utilisation du dialecte.

\subsection{Situation linguistique dans la ville de Šiauliai en Lituanie}

Après avoir fait une analyse des réponses aux enquêtes, on a découvert (diagramme 1) que 33\% des Hauts-Lituaniens et 70\% des Bas-Lituaniens consultés habitant Šiauliai depuis plusieurs années parlent encore leur dialecte. $67 \%$ de Hauts-Lituaniens ne parlent pas le dialecte, mais 33\% d'entre eux l'avaient parlé ou savaient le parler. $30 \%$ de Bas-Lituaniens ne parlent pas le dialecte.

Les enquêtes montrent que $84 \%$ des enfants des Hauts-Lituaniens ne parlent pas le dialecte et $16 \%$ parlent encore le dialecte chez eux, dans la vie quotidienne. Tandis que $40 \%$ des enfants des Bas-Lituaniens parlent encore samogitien, 30\% parlent un patois de Šiauliai, et seulement 30\% ne parlent aucun dialecte.

${ }^{3}$ C'est l'université publique pour les personnes agées qui fonctionne depuis 1999 à Šiauliai (G. Kačiuškienė 2003: 88-89). 


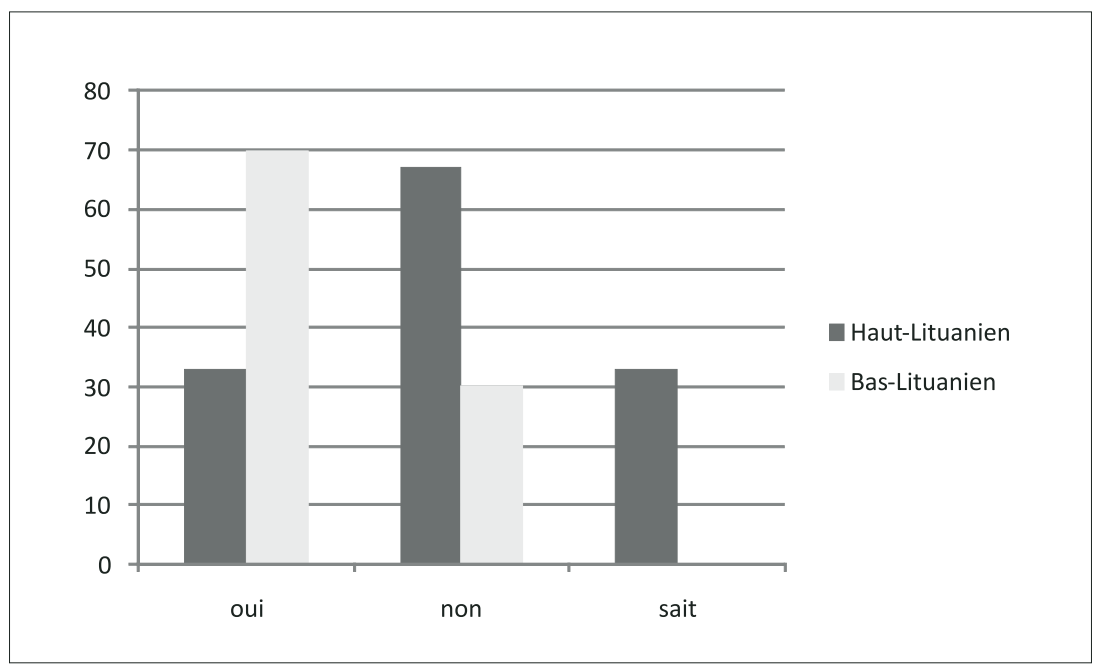

Diagramme 1. Est-ce que vous parlez (ne parlez pas) le dialecte natal?

Les enfants des Bas-Lituaniens parlent leur dialecte dans le village avec les amis, entre eux, ou quand ils sont dans leur région natale.

\subsection{Motivation de parler le dialecte}

À la question pourquoi est-ce que vous parlez le dialecte les Hauts-Lituaniens interrogés ont donné en réponse: que c'était en raison de leur souvenir d'enfance et de jeunesse; qu'il leur permettait de parler plus expressivement; qu'en parlant le dialecte on représentait son coin où on était né et où avait grandi.

Les Bas-Lituaniens parlent leur dialecte parce que: ils peuvent se souvenir de leur enfance; leur parents parlaient ce dialecte; parler le dialecte est intéressant et facile; le dialecte est plus expressif et il permet de s'exprimer à coeur ouvert. L'autre motivation est le souvenir de leurs proches - parents, personnes de la même famille, grands-parents ou l'entourage familial - qui ont appris, tout aussi bien Hauts-Lituaniens que Bas-Lituaniens, à parler le dialecte.

À la question pourquoi certains Hauts-Lituaniens n'aiment pas parler le dialecte, on peut trouver des réponses telles que: le dialecte possède beaucoup de mots étrangers; certains ne le trouvent tout simplement pas beau. Une partie des Hauts-Lituaniens consultés estiment qu'une personne cultivée doit parler la langue littéraire moderne, ils signalent que s'ils parlent leur dialecte leur famille ne les comprend pas et ricane. Les représentants de Basse-Lituanie n'aiment pas parler le dialecte à cause du langage irrégulier. 


\subsection{Fonction esthétique du dialecte}

Aux questions est-ce que vous trouvez votre dialecte natal beau (pas beau)? Pourquoi? (diagramme 2) $41 \%$ des Hauts-Lituaniens trouvent leur dialecte natal beau, 33\% ne le trouvent pas beau, 26\% des Hauts-Lituaniens trouvent leur dialecte natal moyen, étrange, assez rude.

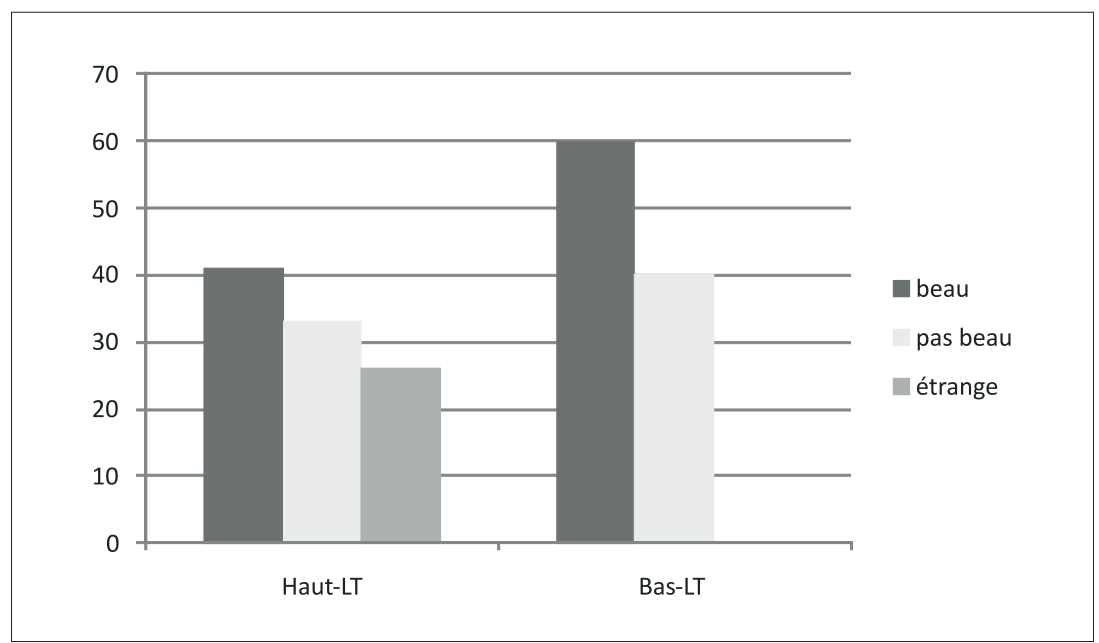

Diagramme 2. Est-ce que vous trouvez votre dialecte natal beau (pas beau)?

$60 \%$ des Bas-Lituaniens interrogés trouvent leur dialecte natal beau, intéressant ou l'aiment tout simplement. $40 \%$ des Bas-Lituaniens ne trouvent pas que leur dialecte soit beau. Malgré cela, $70 \%$ des Bas-Lituaniens et $28 \%$ des Hauts-Lituaniens aiment parler leur dialecte.

\subsection{Localités de utilisation du dialecte}

À la question quand est-ce que vous parlez le dialecte (diagramme 3) 13\% des Hauts-Lituaniens et $32 \%$ des Bas-Lituaniens ont répondu qu'ils parlaient le dialecte avec les gens de la même localité dans le village ou le bourg natal. 10\% des Hauts-Lituaniens et $28 \%$ des Bas-Lituaniens parlent leur dialecte avec les gens de leur localité partout. 10\% des Hauts-Lituaniens et des Bas-Lituaniens ne parlent leur dialecte que chez eux.

Suivant l'opinion des Hauts-Lituaniens il ne convient pas de parler le dialecte pendant les conversations et les présentations officielles, dans les institutions, au travail, dans les émissions de télévision, dans les journaux, pendant les cours, les conférences, quand tout le monde s'exprime en langue littéraire moderne. Les Bas-Lituaniens pensent qu'il ne convient pas de parler le dialecte quand on ne se trouve pas dans le village natal, quand il y a beaucoup de gens, quand 
on se trouve entre personnes qui ne parlent pas le dialecte Bas-Lituanien ou ne le comprennent pas.

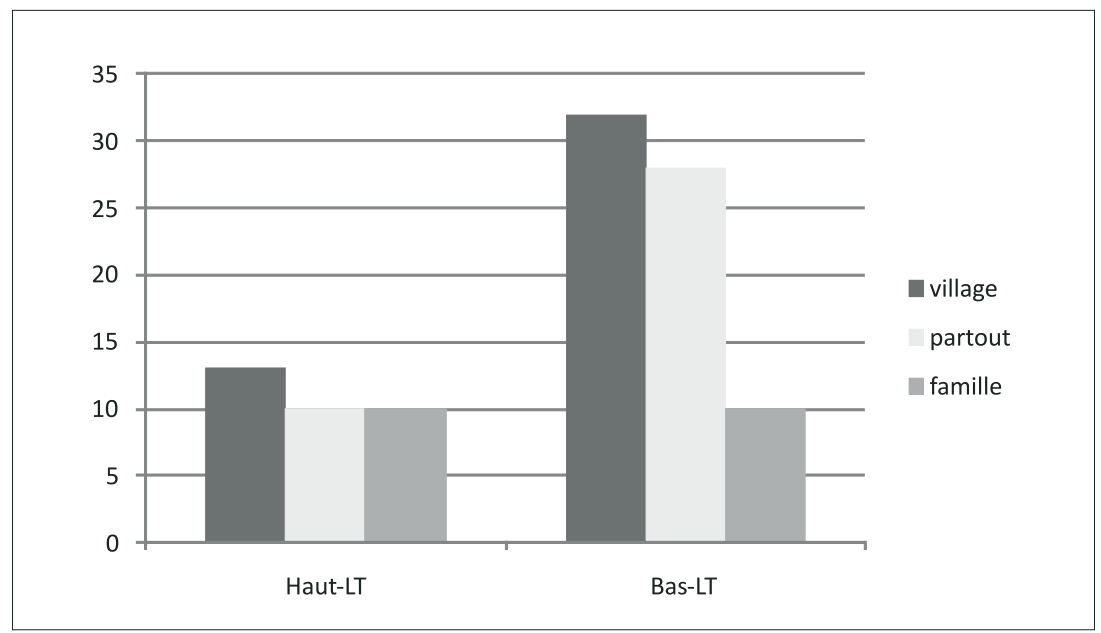

Diagramme 3. Quand est-ce que vous parlez le dialecte?

\section{Analyse comparative des expériences des Hauts-Lituaniens}

Une analyse analogue a été faite en 2003 dans le village de Sidabravas qui se trouve à côté de Šiauliai (à $30 \mathrm{~km}$ ) dans la région de Radviliškis (G. Kačiuškienè 2004: 107-109). On avait interrogé de la même manière un nombre pareil de villageois qui n'ont pas fait d'études supérieures.

Comparons par curiosité des résultats de deux analyses (diagramme 4).

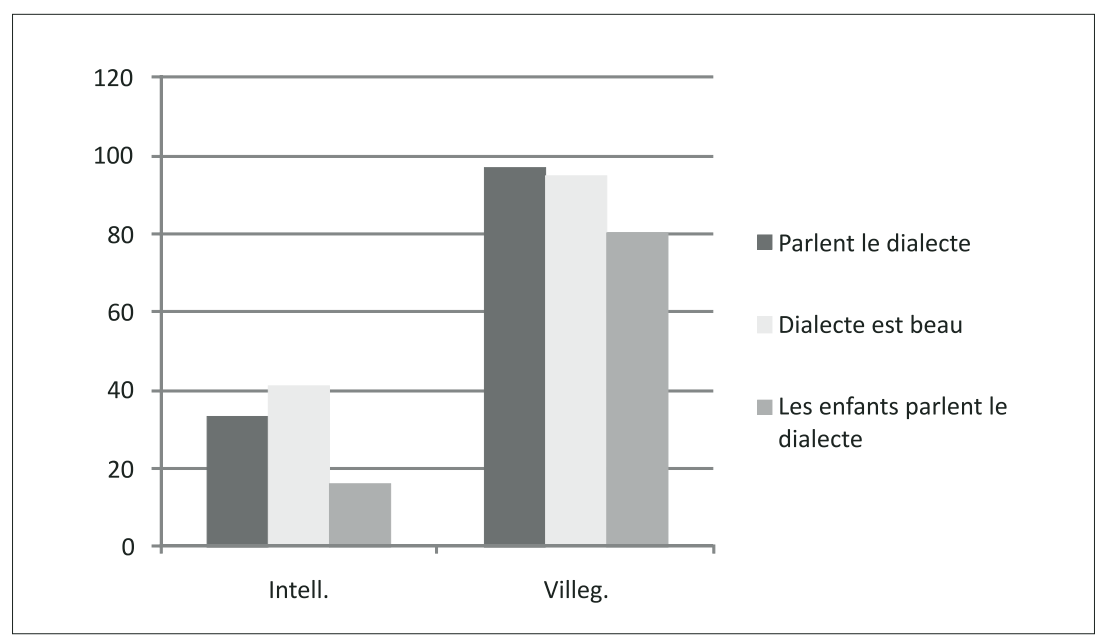

Diagramme 4. Analyse comparative des expériences des Hauts-Lituaniens 
À la question est-ce que vous parlez le dialecte natal $97 \%$ des habitants de Sidabravas ont répondu positivement. Comme les habitants de Šiauliai, ils ont appris à parler leur dialecte le plus souvent par l'intermédiaire de leurs proches: parents et grands-parents. 95\% des villageois aiment parler le dialecte. Ils parlent le dialecte avec les gens de leur localité partout (75\%) ou chez eux (25\%). D'après les villageois, il ne convient pas de parler le dialecte pendant les conversations officielles ou pendant les réunions, dans les institutions, chez le médecin, avec les personnes qui ne comprennent pas le dialecte, avec les jeunes gens, au travail, à l'école, dans les lieux publics, quand on est invité chez quelqu'un, pendant de grands attroupements. Il y avait par contre quelques personnes interrogées qui ont dit qu'il convenait de parler le dialecte partout. À la question est-ce que les enfants parlent le dialecte $80 \%$ des villageois ont répondu positivement. Comme dans les réponses des intellectuels de ville, les habitants de village expliquent que les enfants communiquent en dialecte le plus souvent à la maison, avec des amis, quand ils rentrent dans leur village, à l'école. Il y a des enfants de quelques personnes interrogées qui parlent toujours le dialecte.

Pour la plupart des villageois leur dialecte natal est beau. Les particularités dialectales les plus saillantes sont la réduction des terminaisons et la prononciation plutôt dure de la consonne $l$. Le reste des personnes interrogées ne trouvent pas leur dialecte beau: à cause de l'absence de sonorité; car il détruit la langue littéraire moderne; car le dialecte est très paysan; car on coupe les terminaisons; et car il possède beaucoup de barbarismes. D'après une personne interrogée, tous les dialectes sont laids.

\section{Conclusions}

Sur la base des deux questionnaires (celui des auditeurs intellectuels de la Faculté des sciences humaines de l'Université de Troisième Âge de Šiauliai et celui des habitants du village de Sidabravas de la région de Radviliškis sans éducation supérieure), on peut tirer ces conclusions:

1. Pour les intellectuels de Šiauliai originaires de différentes régions de la Haute-Lituanie (Aukštaitija) et de la Basse-Lituanie (Žemaitija) la conception du dialecte est la même. C'est un langage des parents et du pays natal qui est assez souvent rude et étrange et que chaque génération hérite et ensuite lègue à la suivante en tant que succession reliant cette génération à une histoire du pays et à ses habitants. C'est une langue avec laquelle on peut parler à coeur ouvert avec ses proches dans son pays natal ou chez soi.

2. Dans la perception des intellectuels de la Basse-Lituanie, le dialecte est plus important et est plus valorisé que chez les représentants de la Haute-Lituanie. C'est pourquoi on a découvert un pourcentage plus élevé de Bas-Lituaniens qui parlent le dialecte, davantage de leurs enfants ont hérité le dialecte des parents et parlent le dialecte natal. Les intellectuels hauts-lituaniens (peutêtre à cause des ressemblances de leur dialecte avec la langue littéraire 
moderne ou à cause des particularités caractérielles) abandonnent plus vite leur dialecte natal. Après avoir quitté la maison des parents, ces intellectuels ainsi que leurs enfants communiquent plutôt en langue littéraire.

3. Dans la perception des villageois hauts-lituaniens qui n'ont pas d'éducation supérieure et qui vivent dans un entourage dialectal, le dialecte occupe une place beaucoup plus considérable et joue un rôle beaucoup plus important dans la vie que ce n'était le cas dans la perception des intellectuels de la ville. On le parle presque partout et toujours, on admet et on apprécie ses particularités linguistiques.

4. Les résultats des expériences qu'on a faites permettent d'accepter la conclusion de D. Aliūkaitè (2006: 582) et de R. Urnèžiūtè (1998: 142) que, indépendamment des facteurs tels que l'âge, le lieu de résidence et la classe sociale, l'éducation exerce une grande influence sur la communication dialectale. Plus le niveau d'éducation dans une communauté linguistique est élevé, moins il y a de locuteurs dans cette communauté qui parlent le dialecte.

\section{BIBLIOGRAPHIE}

Daiva ALIŪKAITE், 2006: Tarminio kalbèjimo kultūrinis aspektas / L'aspect culturel de langage parlé. Acta Baltico-Slavica 30, 567-583.

Vytautas AMBAZAS et al., 1997: Lithuanian Grammar / Grammaire lituanienne. Vilnius: Baltos lankos.

Rima BACEVIČIŪTĖ et al., 2004: Lietuviu kalbos tarmiu chrestomatija / Chrestomathie des dialectes lituaniens. Vilnius: Lietuvių kalbos instituto leidykla.

Pietro Umberto DINI, 2000: Baltu kalbos. Lyginamoji analize / Langues baltes. Analyse comparative. Vilnius: Mokslo ir enciklopedijų leidybos institutas.

Genovaitė KAČIUŠKIENĖ, 2003: Trečiojo amžiaus universitetas Šiauliuose: klausytoju požiūris i gimtaja tarmę / Université de Troisième Âge de Šiauliai: l'attitude des auditeurs vers leur dialecte natal. Pedagogika 69, 88-93.

Genovaite KAČIUŠKIENĖ, 2004: Rytu aukštaičiu sidabraviškiu šnektos vertinimas tarmés atstovu požiüriu / Appréciation de dialecte natal par les représentants de Sidabravas de la Haute-Lituanie. Valoda-2004 14. Daugavpils: Daugavpils Universitāte.103-109.

Rita URNĖŽIŪTĖ, 1998: Kodu kaita joniškiečiu šnekamojoje kalboje / Changement de code dans le langage parlé de Joniškis. Kalbotyra 47/1, 131-142.

www.lrytas.lt/str_foto_galerija.asp?id=24045 (vu: 1511 2009). 


\section{RODNO NAREČJE: ANALIZA MNENJA INTELEKTUALCEV IN VAŠČANOV V LITVI}

Prispevek temelji na raziskavi, opravljeni na šiauliajški andragoški fakulteti za humanistične študije. Avtorica poskuša pokazati, kako sta na pojmovanje narečja in na njegovo rabo vplivala mestno okolje in družba, koliko šiauliajških intelektualcev srednjih let, ki so se pred nekaj desetletji izselili iz Litve, še vedno govori litovsko, koliko v narečju in kakšen je njihov odnos do različnih narečij.

Rezultati raziskave kažejo, da pojmovanje rodnega narečja med intelektualci, ki izhajajo iz različnih področij Aukštaitije in Žemaitije, na splošno sovpada. Gre za materni jezik oz. jezik rodne dežele, ki ga sicer pogosto opredeljujejo kot precej čudnega in robatega, a ga kljub temu ohranjajo in prenašajo iz generacije $\mathrm{v}$ generacijo kot dediščino, povezano s predniki, preteklostjo rodne dežele in njenih prebivalcev. V zavesti intelektualcev iz Žemaitije ima narečje pomembno mesto in je vrednoteno višje kot pri intelektualcih iz Aukštaitije.

Aukštaitijci, ki nimajo univerzitetne izobrazbe, pripisujejo narečju veliko večjo vlogo kot šiauliajski intelektualci. 